\title{
Immobilization of Tetrabutyl Thiuram Disulfide in Chitosan Thin Film for Sensing Zinc Ion Using Surface Plasmon Resonance Spectroscopy
}

\author{
Yap Wing Fen*, W. Mahmood Mat Yunus and Zainal Abidin Talib \\ Department of Physics, Faculty of Science, Universiti Putra Malaysia, \\ 43400 UPM Serdang, Selangor, Malaysia
}

(Received July 28, 2011; accepted November 28, 2011)

Key words: surface plasmon resonance, tetrabutyl thiuram disulfide, chitosan, zinc ion

Tetrabutyl thiuram disulfide (TBTDS) immobilized in chitosan thin film has been studied as a sensor element for zinc ion, $\mathrm{Zn}^{2+}$, using surface plasmon resonance (SPR). The TBTDS-immobilized chitosan thin film, which acts as an active layer, was coated on a gold film by spin coating. $\mathrm{Zn}^{2+}$ can be detected by measuring the SPR signal when TBTDS-immobilized chitosan thin film contacts with $\mathrm{Zn}^{2+}$ in solution. The sensor produced a linear response for $\mathrm{Zn}^{2+}$ ranging from 0.1 to $1 \mathrm{ppm}$ with a sensitivity of $0.0317^{\circ} \mathrm{ppm}^{-1}$. Using immobilized TBTDS as an active layer, the $\mathrm{Zn}^{2+}$ can also be selectively detected when present in mixtures of heavy metal ions.

\section{Introduction}

Zinc is one of the essential metals or nutrients for maintaining human metabolism. Zinc is an essential component in a wide variety of metabolic processes, supports a healthy immune system, and is important for normal growth during pregnancy, childhood, and adolescence. ${ }^{(1)}$ However, zinc can be potentially toxic if it is consumed over the daily limit. The recommend dietary allowance (RDA) for zinc is 11 and $8 \mathrm{mg} / \mathrm{d}$ for men and women, respectively. ${ }^{(2)}$ Overdoses of zinc in humans cause severe irritation in the gastrointestinal tract, as well as fever, chest pain, chills, cough, dyspnea, nausea, muscle soreness, fatigue, and leukocytosis.

Owing to the importance and potential for toxicity, several methods have been developed for the detection of $\mathrm{Zn}^{2+}$, including atomic absorption spectroscopy, ${ }^{(3)}$ inductively coupled plasma mass spectroscopy, ${ }^{(4)}$ ratiometric fluorescent probing, ${ }^{(5)}$

${ }^{*}$ Corresponding author: e-mail: yapwingfen@gmail.com 
spectrophotometry, ${ }^{(6)}$ voltammetry, ${ }^{(7)}$ and polarography. ${ }^{(8)}$ However, these methods are generally expensive, require a complicated sample treatment, and often take a long measurement time. Hence, recent analytical interest has focused on developing optical sensors that have the advantages of size, cost-effectiveness, simple preparation of sample, fast measurement capability, and nonrequirement of reference solution. ${ }^{(9-11)}$ Surface plasmon resonance (SPR) spectroscopy, which is one of the optical sensors, has been developed in various configurations and formats for sensing a variety of target samples, including heavy metal ions. ${ }^{(12,13)}$

SPR is an optical process in which light satisfying a resonance condition excites a charge-density wave propagating along the interface between a metal and a dielectric material using a monochromatic and p-polarized light beam. ${ }^{(14)}$ The intensity of the reflected light is reduced at a specific incident angle, producing a sharp shadow due to the resonance energy that occurs between the incident beam and surface plasmon wave (called surface plasmon resonance). The first sensing application of SPR was reported by Liedberg et al. (1983).(15) Since then, numerous SPR sensing structures for chemical and biochemical sensing have been generating continuously growing attention from the scientific community. ${ }^{(16-18)}$ For the past few years, the use of SPR as a heavy ion metal sensor had been widely studied. ${ }^{(19-27)}$ However, SPR has not been applied to the sensitive and selective detection of $\mathrm{Zn}^{2+}$ in aqueous solutions.

Chitosan has been widely used as a chelating agent in the absorption of metal ion owing to the presence of a large number of amino groups on the chitosan chain. ${ }^{(28-39)}$ However, developing chitosan thin film doped with an ionophore as a specific heavy metal ion sensing material to combine with SPR has not been reported. A sensitive ionophore with sulfur donor atoms, i.e., tetrabutyl thiuram disulfide (TBTDS) is expected to provide high sensitivity and selectivity for $\mathrm{Zn}^{2+}$ determination. ${ }^{(40)}$ The structure of TBTDS is shown in Fig. 1. In this work, an attempt has been made to immobilize TBTDS inside chitosan thin film. The potential of TBTDS-immobilized chitosan thin film as an active layer for $\mathrm{Zn}^{2+}$ sensitive and selective detection in the SPR optical sensor is described in this paper.

\section{Materials and Methods}

\subsection{Materials and reagents}

Medium-molecular-weight (MMW) chitosan with a degree of deacetylation of $75-85 \%$ and acetic acid (assay $\geq 99.7 \%$ ) were purchased from Sigma Aldrich (St. Louis, MO, USA). The crosslinker, glutaraldehyde ( $25 \%$ aqueous solution), was purchased

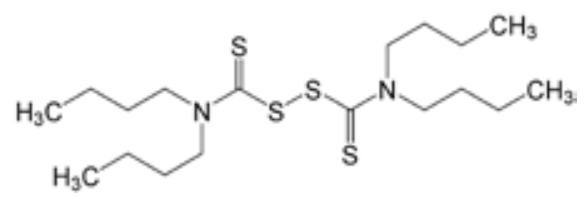

Fig. 1. Structure of sensor material, TBTDS. 
from Alfa Aesar (Ward Hill, MA, USA). The TBTDS was obtained from Fluka (Buchs, Switzerland). Atomic adsorption spectroscopy standard solutions (1000 ppm) of $\mathrm{Zn}^{2+}$, $\mathrm{Pb}^{2+}, \mathrm{Cu}^{2+}, \mathrm{Hg}^{2+}$, and $\mathrm{Mn}^{2+}$ ions were purchased from Merck (Darmstadt, Germany).

\subsection{Preparation of chemicals}

All the chemicals used were of analytical grade, and deionized water was used throughout for solution preparation. A stock TBTDS solution of $2.0 \times 10^{-3} \mathrm{~g} / \mathrm{ml}$ or $0.20 \%(\mathrm{w} / \mathrm{v})$ was prepared by dissolving $100 \mathrm{mg}$ of TBTDS in $50 \mathrm{ml}$ of deionized water. A chitosan solution was prepared by dissolving $0.40 \mathrm{~g}$ of medium-molecularweight chitosan in $50 \mathrm{ml}$ of $1 \%$ acetic acid, $0.05 \mathrm{~g}$ of glutaraldehyde was added to the solution, and then the mixture was stirred thoroughly. Working standard solutions of $\mathrm{Zn}^{2+}$ were prepared by appropriately diluting the $1000 \mathrm{ppm}$ standard solution before use. Multiple metal ion solutions $\left(\mathrm{Zn}^{2+} \mathrm{Mn}^{2+}, \mathrm{Zn}^{2+} \mathrm{Pb}^{2+}, \mathrm{Mn}^{2+} \mathrm{Cu}^{2+}, \mathrm{Zn}^{2+} \mathrm{Pb}^{2+} \mathrm{Mn}^{2+} \mathrm{Hg}^{2+} \mathrm{Cu}^{2+}\right.$, and $\mathrm{Pb}^{2+} \mathrm{Mn}^{2+} \mathrm{Hg}^{2+} \mathrm{Cu}^{2+}$ ) were prepared by mixing the diluted solution (1 ppm) of the required metal ion.

\subsection{Procedure}

A glass cover slip $\left(24 \times 24 \times 0.1 \mathrm{~mm}^{3}\right.$, Menzel-Glaser, Germany) was first deposited with a gold layer using an SC7640 Sputter Coater. Then, spin coating was used to produce a thin layer of TBTDS-immobilized chitosan thin film on the top of the gold layer.

Immobilization of TBTDS inside the chitosan thin film was carried out by mixing $5 \mathrm{ml}$ of $2.0 \times 10^{-3} \mathrm{~g} / \mathrm{ml}$ TBTDS with $45 \mathrm{ml}$ of $1 \%$ chitosan solution. The mixture was stirred thoroughly, spin coated onto the glass cover slips, and covered with a gold layer at $6000 \mathrm{rpm}$ for $30 \mathrm{~s}$ using the Spin Coating System, P-6708D.

\subsection{Instrumentation}

The SPR measurements were carried out for the in situ analysis of the TBTDSimmobilized chitosan thin film using a custom-built instrument. A schematic diagram of the SPR instrument setup used in this work is shown in Fig. 2. A $5 \mathrm{~mW}$ He-Ne laser $(\lambda=$ $632.8 \mathrm{~nm})$ was p-polarized and directed to a prism $(n=1.77861)$, with a glass cover slip, which was coated with gold/TBTDS-immobilized chitosan thin film, attached onto one side of the prism. A cell was constructed and attached to the gold/TBTDS-immobilized chitosan surface to hold the heavy metal ion solution, as shown in Fig. 3. The cell had an O-ring in the middle through which the laser light contacted to the solution. The prism and cell were mounted on a rotating plate to control the angle of the incident light. The reflected beam was detected using a sensitive photodiode and then processed with a lockin-amplifier (SR 530).

\subsection{Atomic Force Microscopy (AFM)}

The gold/TBTDS-immobilized chitosan thin film, before and after $\mathrm{Zn}^{2+}$ adsorption, was imaged by AFM (Q-scope 250, Quesant Instrument Corporation, Agoura Hills, CA) in tapping mode. The scan resolution of 600 was chosen for data acquisition at a scan speed of $2 \mathrm{~Hz}$ under ambient conditions. The sample was measured in air after drying in room temperature. 


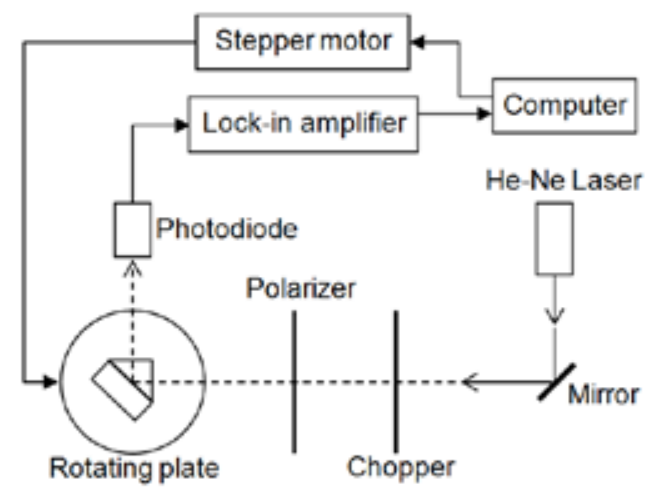

Fig. 2. Experimental setup for angle scan surface plasmon resonance.

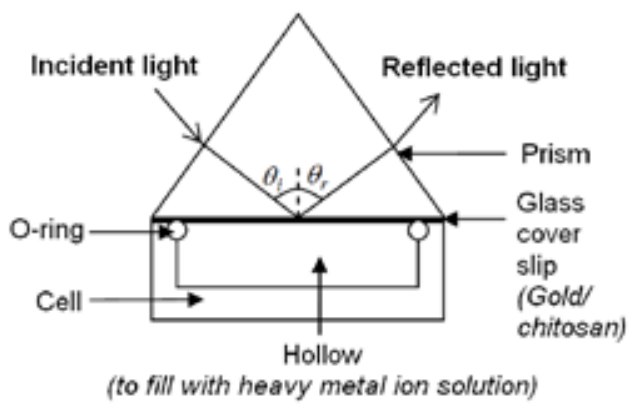

Fig. 3. Structure of the cell for SPR measurement.

\section{Results and Discussion}

First, a preliminary test for deionized water was carried out. About $2 \mathrm{ml}$ of deionized water was injected into the cell in contact with the gold/TBTDS-immobilized chitosan thin film interface. The SPR signal was taken every half a minute and the resonance angle for all times was determined. The resonance angle is constant over time, as shown in Fig. 4.

Different concentrations of $\mathrm{Zn}^{2+}$ in aqueous solution were injected into the cell to be in contact with the gold/TBTDS-immobilized chitosan thin film, and the resonance angle for all the $\mathrm{Zn}^{2+}$ concentrations was determined. The change in the resonance angle $(\Delta \theta)$ can be determined by taking the difference between the resonance angle of the sample and that of deionized water (as a reference). Figure 5 shows the time dependence of the change in resonance angle for $\mathrm{Zn}^{2+}$ that interacts with the gold/TBTDS-immobilized 


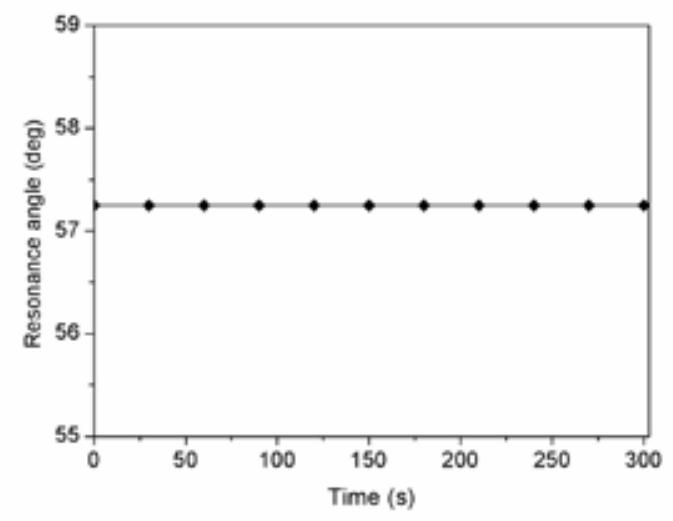

Fig. 4. Resonance angle of deionized water versus time.

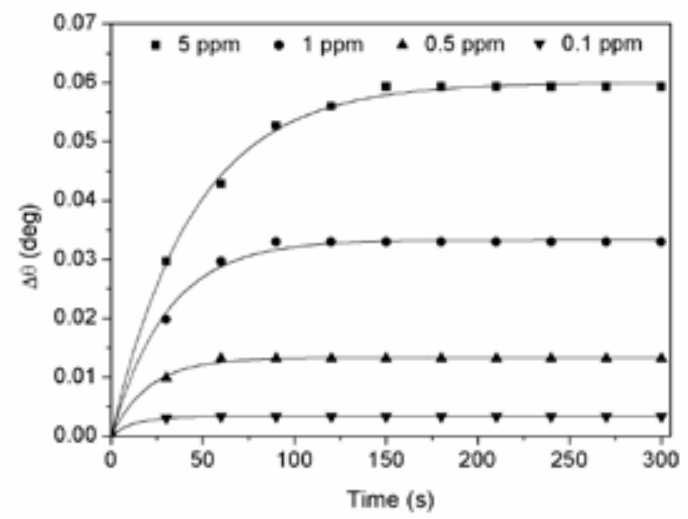

Fig. 5. Change in resonance angle as a function of time for different concentrations of $\mathrm{Zn}^{2+}$ in solution.

chitosan thin film interface at different concentrations down to $0.1 \mathrm{ppm}$. From the figure, we observed that the resonance angle increased with time until it reached a saturation value for all the concentrations of $\mathrm{Zn}^{2+}$.

The relationship between $\mathrm{Zn}^{2+}$ concentration and saturation values of the change in resonance angle $\left(\Delta \theta_{\infty}\right)$ was investigated by plotting the graph of $\Delta \theta_{\infty}$ as a function of $\mathrm{Zn}^{2+}$ concentration, as shown in Fig. 6. The changes in SPR signals mostly depend on the number of ions adsorbed on the gold/TBTDS-immobilized chitosan surface. When the $\mathrm{Zn}^{2+}$ concentration increased, the number of ions also increased, and hence, the signal changes become greater. It means that the more ions on the surface, the greater the observed shift. However, if the surface area is covered and congested with ions, the 


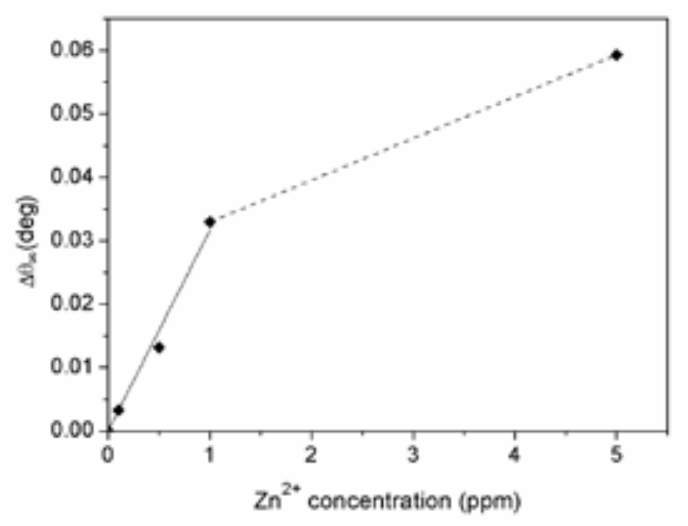

Fig. 6. Saturation value of the change in resonance angle as a function of $\mathrm{Zn}^{2+}$ concentration. The solid line represents the linear fit to the experimental data.

signal change will be decreased. This can be proved from the graph that is linearly fitted for a $\mathrm{Zn}^{2+}$ concentration up to $1 \mathrm{ppm}$, whereas the point above $1 \mathrm{ppm}$ is situated far below the fitted straight line. The value of $\Delta \theta_{\infty}$ is directly proportional to a $\mathrm{Zn}^{2+}$ concentration up to $1 \mathrm{ppm}$, with the slope of the fitted straight line being $0.0317^{\circ} \mathrm{ppm}^{-1}$ and the linear regression coefficient being 0.991 . Therefore, we can conclude that this optical sensor based on TBTDS-immobilized chitosan thin film for $\mathrm{Zn}^{2+}$ is highly sensitive with a sensitivity of $0.0317^{\circ} \mathrm{ppm}^{-1}$, for concentrations below $1 \mathrm{ppm}$.

The SPR experiment was also performed for other metal ion solutions, i.e., $\mathrm{Pb}^{2+}$ $\mathrm{Cu}^{2+}, \mathrm{Hg}^{2+}$, and $\mathrm{Mn}^{2+}$ ions, in contact with the gold/TBTDS-immobilized chitosan thin film. The concentration of the heavy metal ions was fixed at $1 \mathrm{ppm}$. Each heavy metal ion solution was injected into the cell and the change in resonance angle as a function of time was determined, as shown in Fig. 7. We observed that the change in resonance angle is the greatest for the $\mathrm{Zn}^{2+}$ solution as compared with other heavy metal ions, i.e., $\mathrm{Zn}^{2+}>\mathrm{Pb}^{2+}>\mathrm{Hg}^{2+}>\mathrm{Cu}^{2+}>\mathrm{Mn}^{2+}$. Other heavy metal ions revealed a smaller change in the resonance angle with the signals of $\mathrm{Pb}^{2+}, \mathrm{Hg}^{2+}$, and $\mathrm{Cu}^{2+}$ showing comparably higher shifts than the signals of $\mathrm{Mn}^{2+}$.

The morphology of the gold/TBTDS-immobilized chitosan thin film surface after $\mathrm{Zn}^{2+}$ adsorption was determined by AFM and compared with the surface before adsorption, as shown in Fig. 8. The TBTDS-immobilized chitosan surface after $\mathrm{Zn}^{2+}$ adsorption was relatively rougher than that before adsorption. Also, the thickness of the thin film decreased after $\mathrm{Zn}^{2+}$ adsorption, which is most probably due to the reaction that occurred on the surface, which caused the shrinking of the sensor system. Undoubtedly, the adsorption of $\mathrm{Zn}^{2+}$ was enhanced by the immobilization of the chitosan thin film with TBTDS, which increases the change in SPR angle for this ion.

We believe that the immobilization of TBTDS in the chitosan thin film plays an important role in the detection of $\mathrm{Zn}^{2+}$. The TBTDS ionophore structure (Fig. 1), which 


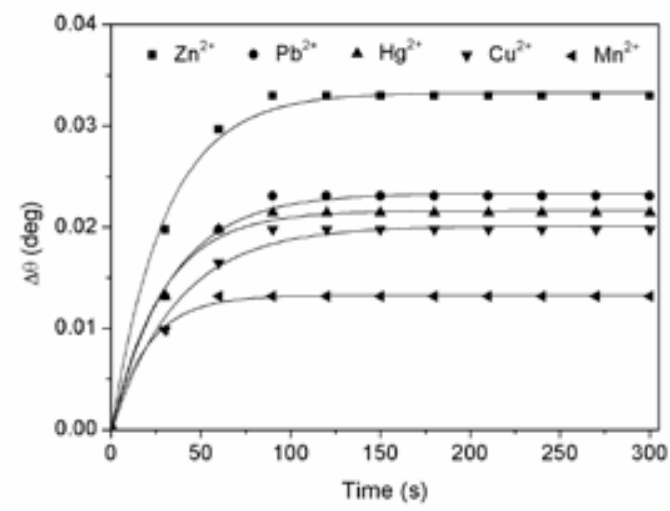

Fig. 7. Change in resonance angle as a function of time for different heavy metal ions (1 ppm each) in contact with gold/TBTDS-immobilized chitosan surface.

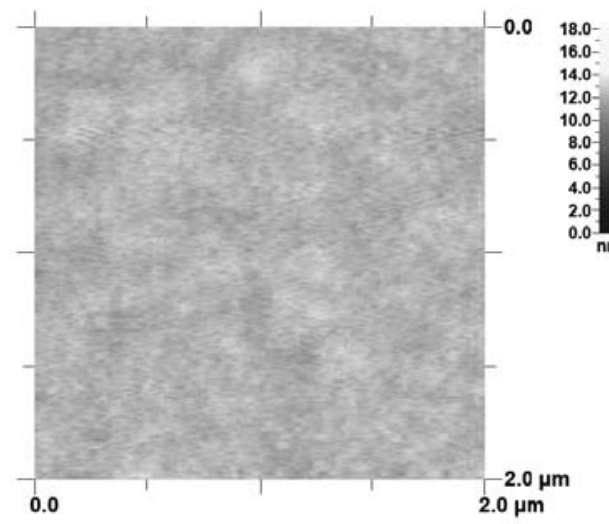

(a)

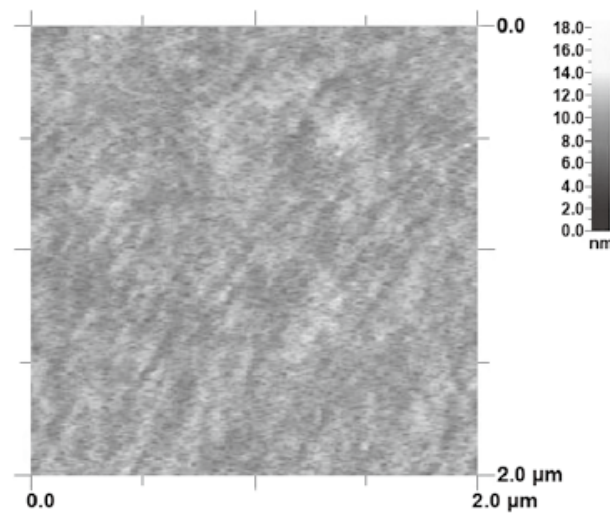

(b)

Fig. 8. AFM images of gold/TBTDS-immobilized chitosan thin film surface: (a) before adsorption; (b) after adsorption of $\mathrm{Zn}^{2+}$.

contains sulfur donor atoms, has the highest affinity towards $\mathrm{Zn}^{2+}$. When the $\mathrm{Zn}^{2+}$ is attached to the thin film, the sulfur donor atoms in TBTDS may form complexes with $\mathrm{Zn}^{2+}$. Furthermore, $\mathrm{Zn}^{2+}$ may interact with the thin film owing to the formation of a pair of shared electrons between the positive charge from the $\mathrm{Zn}^{2+}$ and the negative charge from the amine functional group in chitosan. The lower affinity of the thin film towards other heavy metal ions $\left(\mathrm{Pb}^{2+}, \mathrm{Cu}^{2+}, \mathrm{Hg}^{2+}\right.$, and $\left.\mathrm{Mn}^{2+}\right)$ could be the reason why the change in the resonance angle is relatively smaller than that in the case of $\mathrm{Zn}^{2+}$. 
The same experiments were carried out for multiple metal ion solutions $\left(\mathrm{Zn}^{2+} \mathrm{Mn}^{2+}\right.$, $\mathrm{Zn}^{2+} \mathrm{Pb}^{2+}, \mathrm{Mn}^{2+} \mathrm{Cu}^{2+}, \mathrm{Zn}^{2+} \mathrm{Pb}^{2+} \mathrm{Mn}^{2+} \mathrm{Hg}^{2+} \mathrm{Cu}^{2+}$, and $\mathrm{Pb}^{2+} \mathrm{Mn}^{2+} \mathrm{Hg}^{2+} \mathrm{Cu}^{2+}$ ) to examine the selective detection of $\mathrm{Zn}^{2+}$ in these solutions. These metal ion solutions were prepared by mixing the same volume of $1 \mathrm{ppm}$ single ion solution. Hence, the molar concentrations of $\mathrm{Zn}^{2+} \mathrm{Mn}^{2+}, \mathrm{Zn}^{2+} \mathrm{Pb}^{2+}, \mathrm{Mn}^{2+} \mathrm{Cu}^{2+}, \mathrm{Zn}^{2+} \mathrm{Pb}^{2+} \mathrm{Mn}^{2+} \mathrm{Hg}^{2+} \mathrm{Cu}^{2+}$, and $\mathrm{Pb}^{2+} \mathrm{Mn}^{2+} \mathrm{Hg}^{2+} \mathrm{Cu}^{2+}$ were $17,10,17,12$, and $11 \mu \mathrm{M}$, respectively. The change in resonance angle as a function of time for those solutions is shown in Fig. 9. From the results, the mixed solutions that contain $\mathrm{Zn}^{2+}$ showed the similar increasing trends as observed in the $\mathrm{Zn}^{2+}$ single solution. However, there were slight decreases in the change in the resonance angle for multiple heavy metal ion solutions containing $\mathrm{Zn}^{2+}$ compared with the $\mathrm{Zn}^{2+}$ single ion solution, as shown in Fig. 7. The reductions in the saturated value of the change in resonance angle are most probably attributed to the interference from other metal ions. It is also expected that TBTDS containing sulfur donor atoms will have a stronger interaction with $\mathrm{Pb}^{2+}$ and $\mathrm{Cu}^{2+}$ ions because of the relatively higher affinity of sulfur towards these metal ions. ${ }^{(38)}$ Consequently, the solutions containing both $\mathrm{Pb}^{2+}$ and $\mathrm{Cu}^{2+}$ showed a larger change in resonance angle than the $\mathrm{Mn}^{2+} \mathrm{Cu}^{2+}$ solution. On the other hand, the change in resonance angle for the mixed solutions containing $\mathrm{Zn}^{2+}$ is marginally higher and can be clearly differentiated from the $\mathrm{Mn}^{2+} \mathrm{Cu}^{2+}$ and $\mathrm{Pb}^{2+} \mathrm{Mn}^{2+} \mathrm{Hg}^{2+} \mathrm{Cu}^{2+}$ solutions that contain no $\mathrm{Zn}^{2+}$ even if the molar concentration is similar. Therefore, we conclude that the TBTDSimmobilized chitosan thin film can be used as an active layer to detect $\mathrm{Zn}^{2+}$ selectively in the presence of other heavy metal ions.

\section{Conclusions}

In this work, immobilization of TBTDS in chitosan thin film for the detection of $\mathrm{Zn}^{2+}$ using SPR was developed. By introducing a TBTDS-immobilized chitosan thin film on a gold surface, a $\mathrm{Zn}^{2+}$ concentration range from 0.1 to $5 \mathrm{ppm}$ can be determined.

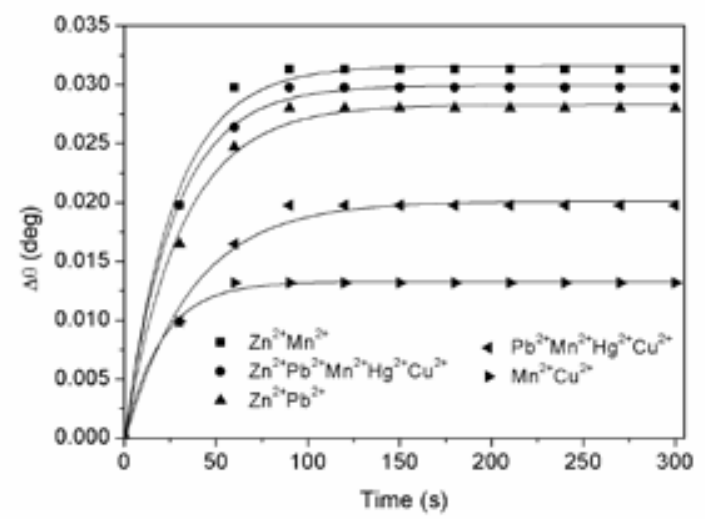

Fig. 9. Change in resonance angle as a function of time for mixed metal ions in contact with gold/ TBTDS-immobilized chitosan surface. 
The saturation value of the change in resonance angle $\left(\Delta \theta_{\infty}\right)$ is directly proportional to the concentration of $\mathrm{Zn}^{2+}$ up to $1 \mathrm{ppm}$, with an observed sensitivity of $0.0317^{\circ} \mathrm{ppm}^{-1}$. The SPR experiment on different heavy metal ion solutions at a concentration of $1 \mathrm{ppm}$ showed that $\mathrm{Zn}^{2+}$ can be differentiated from $\mathrm{Pb}^{2+}, \mathrm{Hg}^{2+}, \mathrm{Cu}^{2+}$, and $\mathrm{Mn}^{2+}$ ions. The change in resonance angle for the mixture of heavy metal ion solutions that contain $\mathrm{Zn}^{2+}$ can be clearly differentiated from the solutions without $\mathrm{Zn}^{2+}$. The above results proved that $\mathrm{Zn}^{2+}$ can be sensitively and selectively detected using this SPR optical sensor with TBTDSimmobilized chitosan thin film as an active layer.

\section{Acknowledgements}

The authors would like to thank the Malaysian Government for the fund support through SAGA and FRGS (No. 5523901) research grants. The laboratory facilities provided by the Department of Physics, Faculty of Science, Universiti Putra Malaysia, are also acknowledged.

\section{References}

1 L. Cai, X. K. Li, Y. Song and M. G. Cherian: Curr. Med. Chem. 12 (2005) 2753.

2 Institute of Medicine, Food and Nutrition Board: Dietary Reference Intakes for Vitamin A, Vitamin K, Arsenic, Boron, Chromium, Copper, Iodine, Iron, Manganese, Molybdenum, Nickel, Silicon, Vanadium, and Zinc (National Academic Press, Washington, 2001).

3 D. C. Hohnadel, F. W. Sunderman, M. W. Nechay and M. D. McNeely: Clin. Chem. 19 (1973) 1288.

4 F. B. M. Wah, T. S. Siu, L. J. S. Kit and S. Tam: Clin. Chem. Lab. Med. 47 (2009) 75.

5 Q.-J. Ma, X.-B. Zhang, Z.-X. Han, B. Huang, Q. Jiang, G.-L. Shen and R.-Q. Yu: Int. J. Environ. Anal. Chem. 91 (2011) 74.

6 C. E. Säbel, J. M. Neureuther and S. Siemann: Anal. Biochem. 397 (2010) 218.

7 O. W. Lau and O. M. Cheng: Anal. Chimica Acta 376 (1998) 197.

8 S. Koçak, Ö. Tokuşoğlu and Ş. Aycan: Electron. J. Environ. Agric. Food Chem. 4 (2005) 871.

9 M. C. Aragoni, M. Arca, F. Demartin, F. A. Devillanova, F. Isaia, A. Garau, V. Lippolis, F. Jalali, U. Papke, M. Shamsipur, L. Tei, A. Yari and G. Verani: Inorg. Chem. 41 (2002) 6623.

10 X.-B. Zhang, C.-C. Guo, Z.-Z. Li, G.-L. Shen and R.-Q. Yu: Anal. Chem. 74 (2002) 821.

11 Y. Kim, R. C. Johnson and J. T. Hupp: Nano Lett. 1 (2001) 165.

12 J. Homola, S. S. Yee and G. Gauglitz: Sens. Actuators, B 54 (1999) 3.

13 J. Mendelez, R. Carr, D. U. Bartholomew, H. Taneja, S. Yee, C. Jung and C. Furlong: Sens. Actuators, B 38 (1997) 375.

14 K. Kurihara and K. Suzuki: Anal. Chem. 74 (2002) 696.

15 B. Liedberg, C. Nylander and I. Lundström: Sens. Actuators, B 4 (1983) 299.

16 S. Miwa and T. Arakawa: Thin Solid Films 281-282 (1996) 466.

17 H. Sota, Y. Hasegawa and M. Iwakura: Anal. Chem. 70 (1998) 2019.

18 A. Abdelghani, J. M. Chovelon, N. Jaffrezic-Renault, C. Ronot-Trioli, C. Veillas and H. Gagnaire: Sens. Actuators, B 38-39 (1997) 407.

19 S. W. Chah, J. H. Yi and R. N. Zare: Sens. Actuators, B 99 (2004) 216.

20 Y. T. Zhang, M. T. Xu, Y. J. Wang, F. Toledo and F. M. Zhou: Sens. Actuators, B 123 (2007) 784.

21 J. Moon, T. Kang, S. Oh, S. Hong and J. Yi: J. Colloid Interface Sci. 298 (2006) 543. 
22 C. M. Wu and L. Y. Lin: Sens. Actuators, B 110 (2005) 231.

23 E. S. Forzani, K. Foley, P. Westerhoff and N. Tao: Sens. Actuators, B 123 (2007) 82.

24 F. Mirkhalaf and D. J. Schiffrin: J. Electroanal. Chem. 484 (2000) 182.

25 A. Sugunan, C. Thanachayanont, J. Dutta and J. G. Hilborn: Sci. Technol. Adv. Mater. 6 (2005) 335.

26 S. M. Lee, S. W. Kang and D. U. Kim: Dyes Pigm. 49 (2001) 109.

27 C. M. Wu and L. Y. Lin: Biosens. Bioelectron. 20 (2004) 864.

28 E. Onsøyen and O. Skaugrud: J. Chem. Technol. Biotechnol. 49 (1990) 395.

29 P. C. Covas, L. W. Alvarez and W. Argüelles-Monal: J. Appl. Polym. Sci. 46 (1992) 1147.

30 Y. Kawamura, M. Mitsuhashi, H. Tanibe and H. Yoshida: Ind. Eng. Chem. Res. 32 (1993) 386.

31 R. Bassi, S. O. Prasher and B. K. Simpson: Sep. Sci. Technol. 35 (2000) 547.

32 L. Qi and Z. Xu: Colloids Surf., A 251 (2004) 183.

33 E. Guibal: Sep. Purif. Technol. 38 (2004) 43.

34 K. H. Chu: J. Hazard. Mater. B 90 (2002) 77.

35 W. S. Wan Ngah, C. S. Endud and R. Mayanar: React. Funct. Polym. 50 (2002) 181.

36 J. D. Merrifield, W. G. Davids, J. D. MacRae and A. Amirbahman: Water Res. 38 (2004) 3132.

37 Y. W. Fen, W. M. M. Yunus and N. A. Yusof: Sens. Mater. 23 (2011) 325.

38 Y. W. Fen, W. M. M. Yunus and N. A. Yusof: Sens. Lett. 9 (2011) 1704.

39 Y. W. Fen, W. M. M. Yunus and N. A. Yusof: Opt. Appl. 41 (2011) 999.

40 R. Kojima and S. Kamata: Anal. Sci. 10 (1994) 409. 